\title{
Effect of temperature and time on solvothermal synthesis of tetragonal $\mathrm{BaTiO}_{3}$
}

\author{
AMIR HABIB $^{1,2, *}$, NILS STELZER ${ }^{2}$, PAUL ANGERER ${ }^{3}$ and ROLAND HAUBNER ${ }^{4}$ \\ ${ }^{1}$ School of Chemical and Materials Engineering, National University of Science and Technology, H/12 Islamabad, Pakistan \\ ${ }^{2}$ Austrian Institute of Technology GmbH, Advanced Materials \& Aerospace Technologies, A-2444 Seibersdorf, Austria \\ ${ }^{3}$ Centre of Electrochemical Surface Technology, A-2700 Wiener Neustadt, Austria \\ ${ }^{4}$ Vienna University of Technology, Getreidemarkt 9/164-CT, A-1060 Vienna, Austria
}

MS received 29 July 2009; revised 16 October 2009

\begin{abstract}
Tetragonal $\mathrm{BaTiO}_{3}$ nanoparticles are synthesized via solvothermal route in an ethanol water mixture. $\mathrm{Ba}(\mathrm{OH})_{2} \cdot 8 \mathrm{H}_{2} \mathrm{O}$ is used as $\mathrm{Ba}$ precursor and $\mathrm{TiO}_{2}(\mathrm{P} 25$ Degussa $\sim 25 \mathrm{~nm}, 30 \%$ anatase, $70 \%$ rutile) is used as $\mathrm{Ti}$ precursor in the $\mathrm{Ba}:$ Ti molar ratio $2: 1$. Effect of temperature and time study on solvothermal synthesis of $\mathrm{BaTiO}_{3}$ revealed that a moderate reaction temperature i.e. $185^{\circ} \mathrm{C}$ and longer reaction time favour tetragonal phase stabilization. Dissolution-precipitation appears to be the transformation mechanism for the crystallization of $\mathrm{BaTiO}_{3}$ from particulate $\mathrm{TiO}_{2}$ precursor.
\end{abstract}

Keywords. Powders—chemical preparation; X-ray methods; electron microscopy; $\mathrm{BaTiO}_{3}$; tetragonal phase.

\section{Introduction}

A prime objective in the barium titanate synthesis is to create smaller, more uniform particles without the loss of dielectric properties via low-temperature synthesis mechanisms. Such finer particles with high relative permittivity may be used in multilayers ceramic capacitors to achieve device miniaturization (Yoon 2006) or embedded in the polymers to achieve thin dielectric layers (Habib et al 2009). Controlling the phase, composition homogeneity, particle size and monodispersity, microstructure, and the cost of particle production are other concerns in developing techniques for synthesizing barium titanate. The stable crystalline polymorph of $\mathrm{BaTiO}_{3}$ at room temperature is the tetragonal form, which possesses a high dielectric constant at temperatures between $0^{\circ} \mathrm{C}$ and $130^{\circ} \mathrm{C}$. Above $130^{\circ} \mathrm{C}$ the unit cell converts to a paraelectric cubic structure (Hench and West 1990). Among various methods for producing sub-micrometer $\mathrm{BaTiO}_{3}$ powder, the hydrothermal technique is well known, however, in all the synthesis reactions below $250^{\circ} \mathrm{C}$, the metastable cubic $\mathrm{BaTiO}_{3}$ stabilizes (Kiss et al 1966; Vivekanandan et al 1987; Habib et al 2008). Hydrothermal synthesis of $\mathrm{BaTiO}_{3}$ resulting in the stabilization of tetragonal form at room temperature has only been reported for syntheses that are carried out above $450^{\circ} \mathrm{C}$ (Christensen 1970; Kajiyoshi et al 1991). Recently, a few authors (Xu and Gao 2003; Kwon et al 2006; Sun et al 2006) have reported the synthesis of tetragonal

\footnotetext{
*Author for correspondence (habib_amir@hotmail.com)
}

$\mathrm{BaTiO}_{3}$ in nanometer size in the temperature range 210$240^{\circ} \mathrm{C}$. Development of strains within the particles in the presence of $\mathrm{OH}^{-}$impurities at lattice sites prevents $\mathrm{BaTiO}_{3}$ from assuming tetragonal phase (Dutta et al 1994). Therefore, a low temperature synthesis procedure that directly results in the formation of tetragonal $\mathrm{BaTiO}_{3}$ is of interest. The present work aims at achieving the tetragonal $\mathrm{BaTiO}_{3}$ in nanometer regime using ethanol-water mixture in $1: 1$ ratio as reaction medium below $200^{\circ} \mathrm{C}$ using $\mathrm{Ba}(\mathrm{OH})_{2} \cdot 8 \mathrm{H}_{2} \mathrm{O}$ and $\mathrm{TiO}_{2}$ (P 25 Degussa $\sim 25 \mathrm{~nm}, 30 \%$ anatase, $70 \%$ rutile).

\section{Experimental}

The Ba to Ti ratio is kept at $2: 1$ in all experiments. Both precursors were weighed and added to a teflon vessel along with distilled water and ethanol in equal amounts i.e. $30 \mathrm{ml}$ each. No mineralizer was used to adjust $\mathrm{pH}$ of the solution. The mixed $\mathrm{Ba}$ and $\mathrm{Ti}$ precursors were treated at different temperatures, 165,185 and $235^{\circ} \mathrm{C}$, for different reaction times in an autoclave (BLH800, Berghof, Germany) under autogenous pressure. All reactions took place at set times after the temperatures had reached a desired value. The obtained slurry was washed with $100 \mathrm{ml}$ of $1 \mathrm{M}$ formic acid and then dried in an oven at $100^{\circ} \mathrm{C}$. The resulting dry cake was ground using an agate mortar to obtain $\mathrm{BaTiO}_{3}$ powders.

The phase analysis of the samples was carried out by means of powder XRD methods (Young 1993; Dinnebier and Billinge 2008). For this purpose an X'Pert device (BraggBrentano diffraction geometry, manufactured by Philips 
Panalytical, the Netherlands) was used. This apparatus uses $\mathrm{CuK} \alpha$ radiation $(0.15406 \mathrm{~nm}$ wavelength) and is equipped with an automatic divergence slit, a graphite monochromator, and a scintillation counter. The measurements were conducted in step-scan mode in the range of $5-85^{\circ} 2 \theta$ with a step size of $0.025^{\circ}$. The XRD data evaluation (lattice parameters, crystallite size) was performed using the Rietveld analysis software package TOPAS by Bruker AXS, Germany (AXS 2005). A high resolution scanning electron microscopy HRSEM ZEISS - Gemini Supra VP was used to investigate the particle size and morphology of the sample powders.

\section{Results and discussion}

The various samples obtained during solvothermal synthesis are shown in table 1 . All the samples were obtained using $\mathrm{Ba}$ : Ti ratio $=2: 1$ in ethanol to water mixture $(1: 1)$.

\subsection{Crystal structure and phase}

Figure 1(a) shows the X-ray diffraction patterns of obtained samples of $\mathrm{BaTiO}_{3}$ powders. The perovskite structure is evident in all the samples. No impurities like $\mathrm{BaCO}_{3}$ or $\mathrm{TiO}_{2}$ are observed in the samples indicating the crystallization of pure $\mathrm{BaTiO}_{3}$. XRD patterns of obtained $\mathrm{BaTiO}_{3}$ for samples reacted at $185^{\circ} \mathrm{C}$ for 6 days shows a clear split of (002) and (200) peaks at $44.85^{\circ} 2 \Theta$ and $45.38^{\circ} 2 \Theta$. This split decreases for shorter duration of reactions whereas at $165^{\circ} \mathrm{C}$ after 4 days the split becomes minimal.

\subsection{Tetragonality c/a}

The ' $a$ ' and ' $c$ ' cell parameters were calculated using Rietveld analysis. The tetragonality is calculated in terms of cla ratio for sample powders as shown in table 1 . The highest value of $c / a=1.00828$ is obtained for samples synthesized by solvothermal processing at $185^{\circ} \mathrm{C}$ for 6 days.

The lowest value of $c / a=1.00611$ is observed for samples reacted at $165^{\circ} \mathrm{C}$ for 4 days. The samples obtained at $185^{\circ} \mathrm{C}$ after 3 days, at $235^{\circ} \mathrm{C}$ for 1 day and $185^{\circ} \mathrm{C}$ after 2 days have values close to each other. An increase in the value of $c / a$,

Table 1. Crystallite size using XRD data and particle size from SEM images with different tetragonality $(c / a)$ ratios for obtained $\mathrm{BaTiO}_{3}$ powders.

\begin{tabular}{lccccc}
\hline & Temperature & Time & Crystallite & Particle size \\
Sample & $\left({ }^{\circ} \mathrm{C}\right)$ & (days) & size XRD (nm) & SEM (nm) & $c / a$ \\
\hline EtOH-1 & 185 & 6 & 66 & 120 & $1 \cdot 008$ \\
EtOH-2 & 185 & 3 & 64 & 90 & 1.007 \\
EtOH-3 & 185 & 2 & 48 & - & 1.007 \\
EtOH-4 & 235 & 1 & 47 & 100 & 1.007 \\
EtOH-5 & 165 & 4 & 57 & 90 & 1.006 \\
\hline
\end{tabular}

with increase in reaction time i.e. 2, 3, and 6 days, is observed for samples reacted at $185^{\circ} \mathrm{C}$.

\subsection{Crystallite size}

Table 1 shows that the crystallite size obtained by the Rietveld calculations of the prepared powders remained between 47 and $66 \mathrm{~nm}$. For powders obtained at $185^{\circ} \mathrm{C}$, an increase in $c / a$ with an increase in crystallite size is observed. The crystallite size of the sample obtained at $185^{\circ} \mathrm{C}$ after 6 days is $66 \mathrm{~nm}$. The crystallite size for the sample obtained at $165^{\circ} \mathrm{C}$ after 4 days is $57 \mathrm{~nm}$.

\subsection{Particle size and morphology}

Figure 2 shows scanning electron micrographs of the obtained $\mathrm{BaTiO}_{3}$ powders. For all the samples, the homogenous size distribution remains to be a typical characteristic of powders obtained via this solvothermal route.

The particle size appears to increase with reaction time. The particle size for samples obtained at $185^{\circ} \mathrm{C}$ after 6 days is around $120 \mathrm{~nm}$, whereas its value is around $80-90 \mathrm{~nm}$ at same temperature after 3 days.

No trend of particle size variation is predictable on the basis of reaction temperatures (figure 3 ).

The morphology of obtained powders remains rectangular for a reaction temperature of $185^{\circ} \mathrm{C}$. The samples obtained at $235^{\circ} \mathrm{C}$ after 1 day as well shows the rectangular shape of nanoparticles, whereas spherical particles are observed for a reaction temperature of $165^{\circ} \mathrm{C}$.

The combined effect of solvent, temperature, pressure and time on the ionic reaction equilibrium stabilizes desirable single or multiple complex oxides during a hydrothermal/solvothermal process. The effect of synthesis conditions i.e. reaction temperature, and time on the formation of tetragonal phase of $\mathrm{BaTiO}_{3}$ observed in this work is supported by literature and is discussed here.

\subsection{Crystal structure and phase}

No unreacted $\mathrm{TiO}_{2}$ is observed in the samples indicating the crystallization of pure perovskite $\mathrm{BaTiO}_{3}$. Use of $\mathrm{Ba} / \mathrm{Ti}>$ 1 is beneficial for achieving phase pure $\mathrm{BaTiO}_{3}$ (Habib et al 2008). The splitting of the (200) reflection with the lower angle shoulder indexed at (002) is an indication of tetragonal form of $\mathrm{BaTiO}_{3}$ (Dutta et al 1994; Wu et al 1996; Lu et al 2000). In the cubic form this peak remains unsplit. The double peak is obvious in all the samples with varying amounts of tetragonality. Figure 1(b) shows these splitting peaks clearly, whereas figure 3(a) shows the corresponding variation of $c / a$ ratios. This indicates that stabilization of tetragonal phase of $\mathrm{BaTiO}_{3}$ is dependent on reaction temperature and time. The $c / a$ value and amount of splitting is observed to increase for a reaction temperature $\left(185^{\circ} \mathrm{C}\right)$ as 


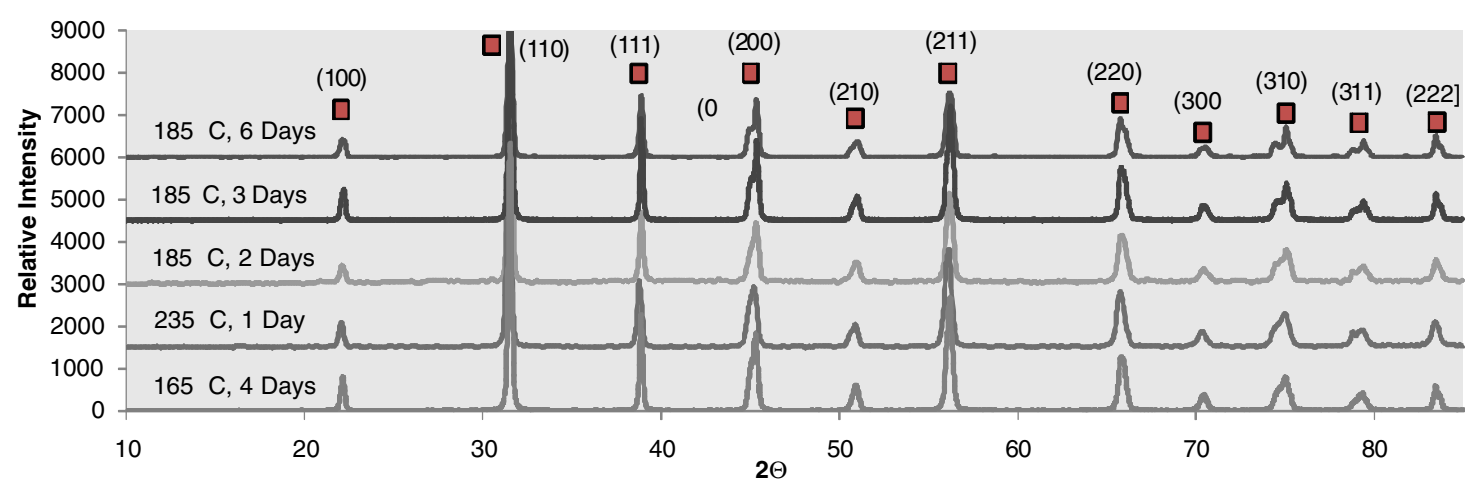

(a)

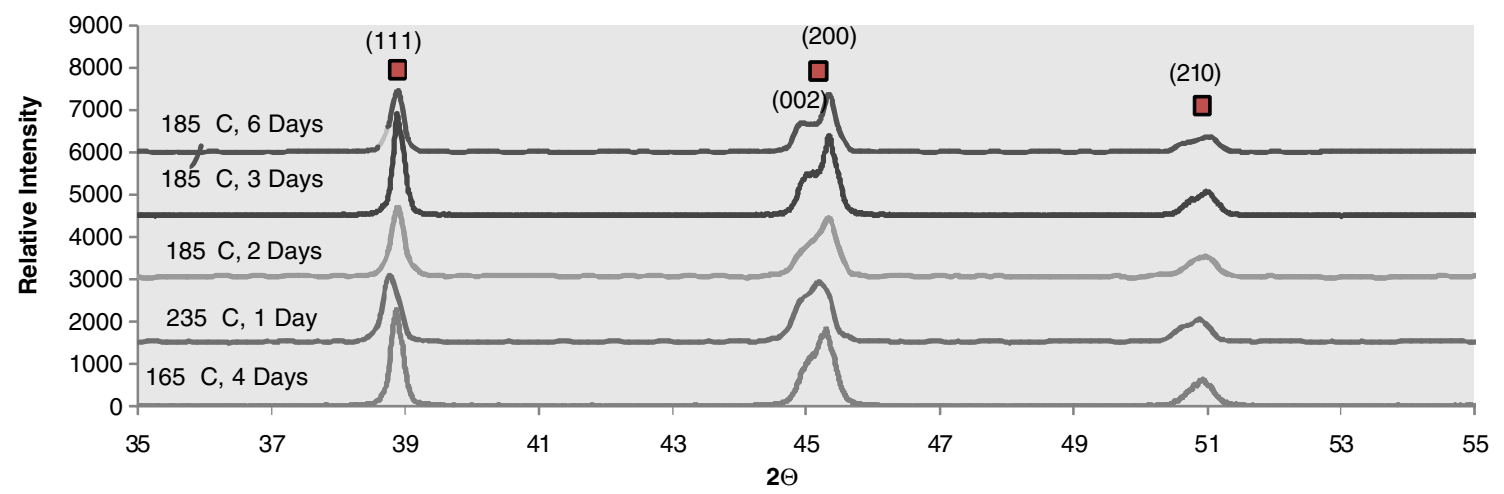

(b)

Figure 1. (a) XRD patterns of obtained $\mathrm{BaTiO}_{3}$ samples, (b) enlarged portion of the graph to indicate the clear split in (002) and (200) peaks around $45^{\circ} 2 \Theta$ angles.

the reaction time increases. Product at low reaction temperature i.e. $165^{\circ} \mathrm{C}$, for four days has minimum $c / a$ and split, whereas the reaction at $235^{\circ} \mathrm{C}$ for 1 day has as well yielded low tetragonality powder. This hints towards the slow crystallization kinetic of tetragonal $\mathrm{BaTiO}_{3}$. The same was found by Dutta and Gregg (1992) and Wu et al (1999), who reported hydrothermal synthesis of tetragonal $\mathrm{BaTiO}_{3}$ after several days of reaction time.

\subsection{Influence of ethanol during synthesis of $\mathrm{BaTiO}_{3}$ powders}

Presence of ethanol is another important factor that helps to form tetragonal phase of $\mathrm{BaTiO}_{3}$ as reported by Kwon et al (2006). In a way our results enforce the idea of Kwon et al (2006) that $\mathrm{OH}^{-}$plays a vital role in stabilization of tetragonal phase. It is, however, difficult to say how $\mathrm{OH}^{-}$contributes to it, as the reaction in nonaqueous solution is complex and there is currently limited information available regarding kinetics and underlying crystallization mechanism. Two proposed mechanisms of formation of $\mathrm{BaTiO}_{3}$ from $\mathrm{Ba}^{2+}$ and $\mathrm{Ti}$ species involve a condensation reaction of $\mathrm{Ti}(\mathrm{OH})_{6}^{2-}$ with $\mathrm{Ba}^{2+}$ (Vivekanandan et al 1987) and migration of $\mathrm{Ba}^{2+}$ into the $\mathrm{TiO}_{2}$ structure with resulting breakage of Ti-O-Ti bonds and incorporation of $\mathrm{Ba}^{2+}$ (Kiss et al 1966; Dutta and Gregg
1992). In the latter mechanism, the role of $\mathrm{OH}^{-}$ions could be to facilitate the hydrolysis of Ti-O-Ti bonds.

Chen and Jiao (2000) found the formation of $\mathrm{BaTiO}_{3}$ difficult in solvothermal synthesis than in hydrothermal method. They reported the synthesis of cubic $\mathrm{BaTiO}_{3}$ powders of $<60 \mathrm{~nm}$ using ethanol and attributed loss of tetragonality to low permittivity of the solvent. However, this study, supported by Kwon et al (2006), shows that the ethanol itself is not detrimental, rather it is effective for tetragonal $\mathrm{BaTiO}_{3}$ synthesis.

\subsection{Tetragonality ratio and particle size effect}

Begg et al (1994) reported that the largest $c / a$ ratio was 1.010 for hydrothermally synthesized $\mathrm{BaTiO}_{3}$ powders. Earlier literature (Buessem et al 1966; Bell et al 1984; Arlt et al 1985; Arlt 1987; Kanata et al 1987; Dutta and Gregg 1992) reported that to stabilize tetragonal $\mathrm{BaTiO}_{3}$, it is important that crystal size should exceed $1 \mu \mathrm{m}$ to accommodate the strains caused by the transformation from cubic to tetragonal structure. Few successful cases of tetragonal $\mathrm{BaTiO}_{3}$ powder synthesis below $100 \mathrm{~nm}$ size have been reported recently ( $\mathrm{Lu}$ et al 2000; Zhang et al 2001; Xu and Gao 2003; Kwon et al 2006). This study reports the synthesis of $\mathrm{BaTiO}_{3}$ powders at $185^{\circ} \mathrm{C}$ with crystallite size, $66 \mathrm{~nm}$ and high tetragonality 


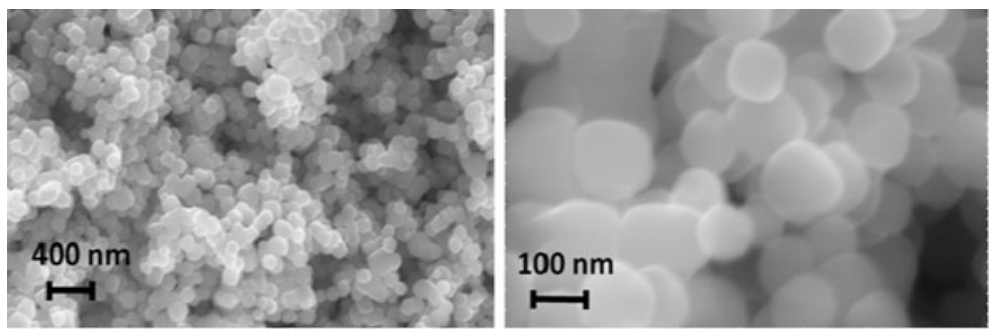

$\mathrm{BaTiO}_{3}$ Obtained at $185^{\circ} \mathrm{C}$ for 6 Days

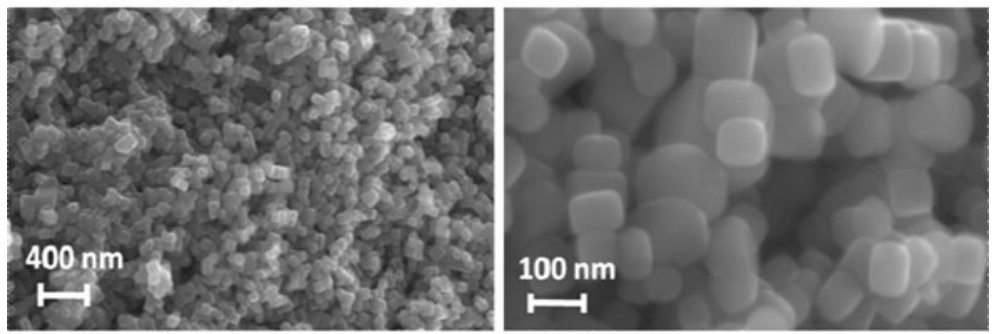

$\mathrm{BaTiO}_{3}$ Obtained at $235^{\circ} \mathrm{C}$ for 1 Day

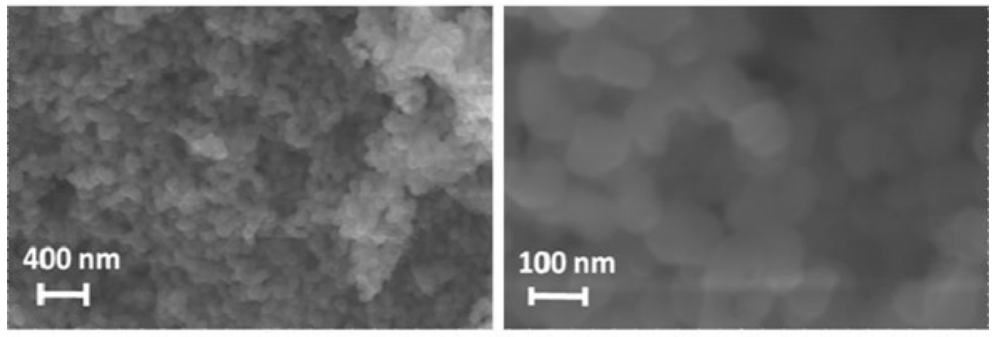

$\mathrm{BaTiO}_{3}$ Obtained at $185^{\circ} \mathrm{C}$ for 3 Days

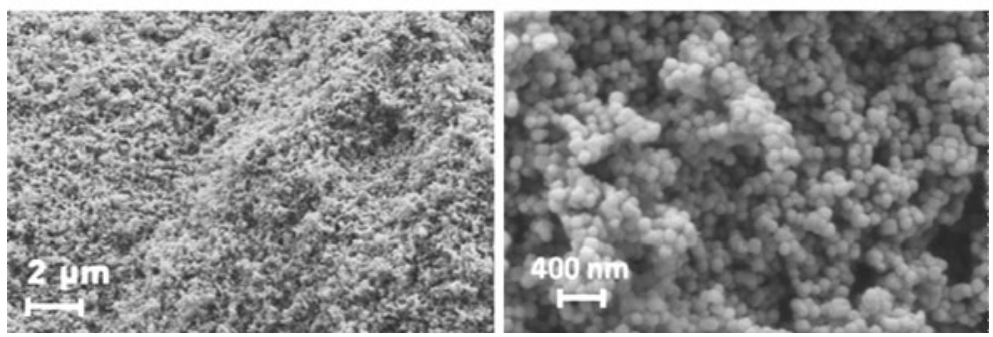

$\mathrm{BaTiO}_{3}$ Obtained at $165^{\circ} \mathrm{C}$ for 4 Days

Figure 2. SEM micrographs of obtained $\mathrm{BaTiO}_{3}$ powders.

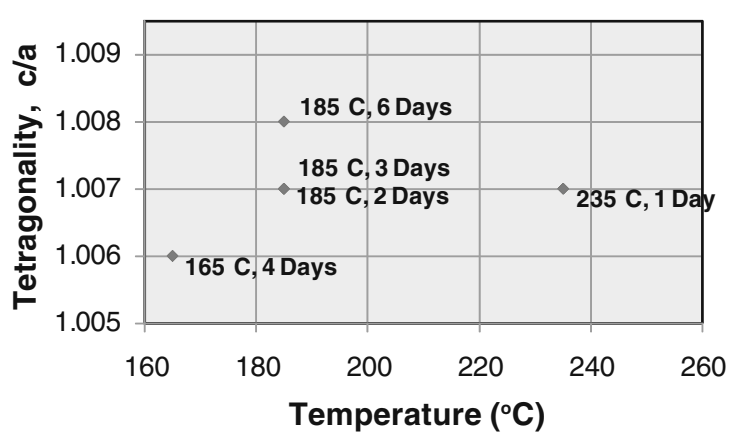

(a)

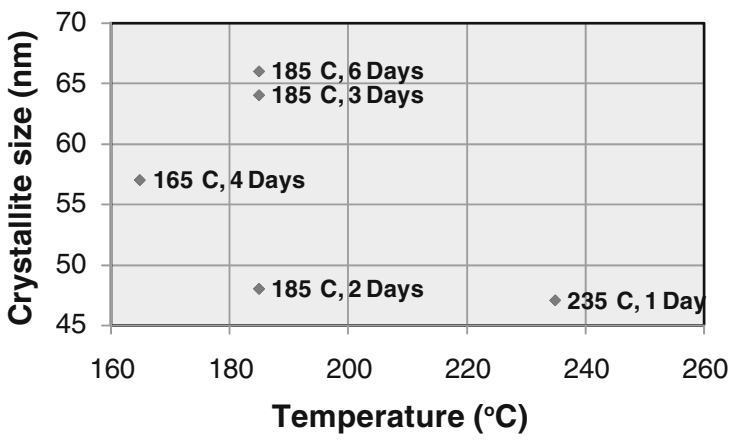

(b)

Figure 3. (a) Tetragonality, and (b) crystallite size (nm) for different processing temperatures and times of obtained $\mathrm{BaTiO}_{3}$ nanopowders. 
$(c / a \sim 1.008)$ (figure 3 ). This is, to the best of our knowledge, the lowest reaction temperature with this high tetragonality reported in literature although the reaction time here is quite long i.e. 6 days.

It is generally believed that there is a decrease in tetragonal distortion with decreasing particle size below $1 \mu \mathrm{m}$. Arlt et al (1985) reported that at grain sizes $<0.7 \mu \mathrm{m}$ the permittivity strongly decreases and the lattice gradually changes from tetragonal to pseudocubic. Uchino et al (1989) showed that the transformation from tetragonal to cubic symmetry occurred at a critical particle size of $0.12 \mu \mathrm{m}$. Begg et al (1994), however, indicated that a hydrothermal $\mathrm{BaTiO}_{3}$ powder with a particle size $>0.27 \mu \mathrm{m}$ was completely tetragonal and with a particle size $<0.19 \mu \mathrm{m}$ was a fully cubic phase. In this study largest $c / a$ value of 1.008 is observed for crystallite size, $\sim 66 \mathrm{~nm}$ (figure 3 ). An increase in particle size is observed with increase in reaction time.

\subsection{Transformation mechanism}

The size and morphology of obtained product is quite different from the initial Ti-precursor (SEMs for $\mathrm{TiO}_{2}$ are available elsewhere (Habib et al 2008)). This suggests that in situ transformation mechanism may not be crystallization mechanism for the formation of $\mathrm{BaTiO}_{3}$ particles. Dissolution of $\mathrm{TiO}_{2}$ into $\mathrm{Ti}(\mathrm{OH})_{x}^{4-x}$ species must have occurred and precipitated $\mathrm{BaTiO}_{3}$ nucleation by reaction with barium ions or complexes in solution, followed by recrystallization or growth i.e. dissolution-precipitation transformation mechanism. Barium titanate particles obtained by this route are usually different from the precursor titania particles with regard to their size and shape (Eckert et al 1996; Hu et al 2000).

\section{Conclusions}

Tetragonal $\mathrm{BaTiO}_{3}(\sim 66 \mathrm{~nm})$ nanopowders are synthesized via solvothermal route using an equal ratio of ethanol-water mixture. The $c / a$ value of the $\mathrm{BaTiO}_{3}$ powder samples prepared at $185^{\circ} \mathrm{C}$ increases with reaction time. The highest tetragonality $(c / a=1.00828)$ is observed for samples reacted at $185^{\circ} \mathrm{C}$ for 6 days. The use of ethanol along with water as a solvent in 1:1 ratio proved to be beneficial in stabilization of tetragonal $\mathrm{BaTiO}_{3}$. The dissolution-precipitation appears to be a responsible transformation mechanism for the crystallization of $\mathrm{BaTiO}_{3}$ from particulate $\mathrm{TiO}_{2}$ precursor.

\section{References}

Arlt G 1987 Ferroelectrics 76451

Arlt G, Hennings D and de With G 1985 J. Appl. Phys. 581619

AXS B 2005 TOPAS V3: General profile and structure analysis software for powder diffraction data, Karlsruhe

Begg B D, Vance E R and Nowotny J 1994 J. Am. Ceram. Soc. 77 3186

Bell A J, Moulson A J and Cross L E 1984 Ferroelectrics 54487

Buessem W R, Cross L E and Goswami A K 1966 J. Am. Ceram. Soc. 4933

Chen D and Jiao X 2000 J. Am. Ceram. Soc. 832637

Christensen A N 1970 Acta Chem. Scand. 242447

Dinnebier R E and Billinge S J L 2008 Powder diffraction-theory and practice (Cambridge, UK: The Royal Society of Chemistry)

Dutta P K and Gregg J R 1992 Chem. Mater. 4843

Dutta P K, Asiaie R, Akbar S A and Zhug W 1994 Chem. Mater. 6 1542

Eckert J O Jr, Hung-Houston C C, Gersten B L, Lencka M M and Riman R E 1996 J. Am. Ceram. Soc. 792929

Habib A, Stelzer N and Haubner R 2008 Mater. Sci. Eng. B152 60

Habib A, Stelzer N and Haubner R 2009 Solid State Phenom. 151 108

Hench L L and West J K 1990 Principles of electronic ceramics (New York: Wiley)

Hu M, Kurian V, Payzant E, Andrew R, Claudia J and Hunt R D 2000 Powder Technol. 1102

Kajiyoshi K, Ishizawa N and Yoshimura M 1991 J. Am. Ceram. Soc. 74369

Kanata T, Yoshikawa T and Kubota K 1987 Solid State Commun. 62765

Kiss K, Magder J, Vukasovich M S and Lockhart R J 1966 J. Am. Ceram. Soc. 49291

Kwon S-G, Park B-H, Choi K, Choi E-S, Namb S, Kimc J-W and Kimc J-H 2006 J. Eur. Ceram. Soc. 261401

Lu S W, Lee B I, Wang Z L and Samuels W D 2000 J. Cryst. Growth 219269

Sun W, Li C, Li J and Liu W 2006 Mater. Chem. Phys. 97481

Uchino K, Sadanaga E and Hirose T 1989 J. Am. Ceram. Soc. 72 1555

Vivekanandan R, Phillip S and Kutty T R N 1987 Mater. Res. Bull. 2299

Wu M, Xu R, Feng S H, Li L, Chen D and Luo Y 1996 J. Mater. Sci. 366201

Wu M, Junbiao L, Wang G, Huang A and Luo Y 1999 J. Am. Ceram. Soc. 823254

Xu H and Gao L 2003 J. Am. Ceram. Soc. 86203

Yoon D-H 2006 J. Ceram. Process. Res. 7343

Young R A 1993 The Rietveld method (New York: Oxford University Press Inc.)

Zhang M S, Yin Z, Chen Q, Zhang W and Chen W 2001 Solid State Commun. 119659 